\title{
NEW APPROACH FOR PREDICTION THE DC BREAKDOWN VOLTAGE USING FUZZY LOGIC CONTROLLER
}

\author{
Abdelghani ROUINI ${ }^{1}$, Nabil DERBEL ${ }^{2}$, Ahmed HAFAIFA $^{1}$, Abdellah KOUZOU ${ }^{1}$ \\ ${ }^{1}$ Applied Automation and Industrial Diagnostics Laboratory, Faculty of Science and Technology, \\ University of Djelfa 17000 DZ, Algeria. \\ e-mails: abdrouini@gmail.com; hafaifa.ahmed.dz@ieee.org, kouzouabdellah@ieee.org \\ ${ }^{2}$ Control and Energy Management Laboratory (CEM Lab), National Engineering School of Sfax \\ University of Sfax, Tunisia, e-mail: n.derbel@enis.run.tn
}

\begin{abstract}
High voltage device design needs predicting the withstanding voltage to assay conditions as pulses, surges and the DC voltage. There is a great designer needed to have reliable design requirements and welldefined simulation procedure for the development of the apparatus. In this paper, Fuzzy Logic (FL) method is used to model breakdown voltage, based on experimental data generated in the laboratory. Different models are proposed with different membership functions for the FL under both DC voltage conditions. The purpose of this article is to investigate the discharge phenomenon for an air gap-point plan at with insulation barrier between themselves. Obtained results are encouraging. Proving that fuzzy logic is a powerful tool that can be used in predicting the properties of the barrier.
\end{abstract}

Keywords: Fuzzy logic Controller, Number of partitions, Breakdown voltage, Barrier, Point-Plane.

\section{INTRODUCTION}

Barriers are used in largely several highvoltage devices. It has been known that the dielectric of the strength of the long gap is significantly increased by inserting an insulating barrier. Each insulating structure gives particular discharge phenomenon [1-4].

Knowing the ionization state and the spread of electric discharge are of great importance to fully understand the mechanism behind the breakdown [5-9].

The insertion of the barrier near the sharp electrode has a great influence on the dielectric strength [10-15].

The effectiveness of the barrier depends on the geometry and position and the physical nature of the barrier. The survey has been simulated and conducted experimentally and to study the barrier breakdown phenomenon [16-22].

As a result, three materials have the same effect on the barrier. The breakdown voltage varies with the size of the barrier, and the maximum flashover voltages is observed where the barrier is positioned at the closest point the electrode [23-31].

The small size of barrier becomes effective in very small air spaces.

Based experimental results, a Sugeno fuzzy logic system is modelled to predict DC breakdown voltage, in terms of the relative position of the barrier, the hole, the width of the barrier, and the nature of the barrier. In fact, the breakdown phenomenon depends on this variable [32-34].
In this paper, details of a proposed method for the prediction of electric discharge in air using fuzzy logic.

The use of the fuzzy logic technique allows us to have a numerical system that can predict the electric discharge using the fuzzy reasoning.

The difficulty of obtaining a mathematical model which can reflects the evolution of the electric discharge in the field of high voltage has obliged several researchers to introduce different analysis and methods to study such a subject [3536]. In this work, to use the fuzzy logic technique based on experimental data to predict the electrical discharge in a point-to-plane system.

The used database are collected from tests conducted at the high-voltage laboratory of the University of Biskra.

\section{EXPERIMENTAL SETUP}

The experimental set-up consists of a highvoltage test transformer $100 \mathrm{kV} / 5 \mathrm{kVA} / 50 \mathrm{~Hz}$, a capacitive voltage divider. Fig 1 and Fig 2 (the experiences have been performed in the laboratory of high voltage University of Biskra).

Shows the arrangement of electrodes and insulating barrier it contains a point-plan electrode arrangement mounted vertical. The HV electrodes consist a steel needlepoint on copper of conical in shape $30^{\circ}$. The grounded plan electrode is a circular steel plate of $30 \mathrm{~cm}$ long, $2.8 \mathrm{~cm}$ diameter. 
The plexiglas barriers $(\boldsymbol{\varepsilon} \boldsymbol{r}=3.3)$, the second type of barrier used is bakelite $(\boldsymbol{\varepsilon} \boldsymbol{r}=5.82)$, and The third type of barrier used is Glass barriers $(\boldsymbol{\varepsilon} r=6)$, are squares of different widths $(5 \mathrm{~cm}, 10 \mathrm{~cm}, 15 \mathrm{~cm})$ and different holes $(4 \mathrm{~mm}, 8 \mathrm{~mm}$ and $12 \mathrm{~mm})$ and its thicknesses is $1 \mathrm{~mm}$, an aluminium plan grounded. To change the positions for several barriers, carriers Bakelite are used.

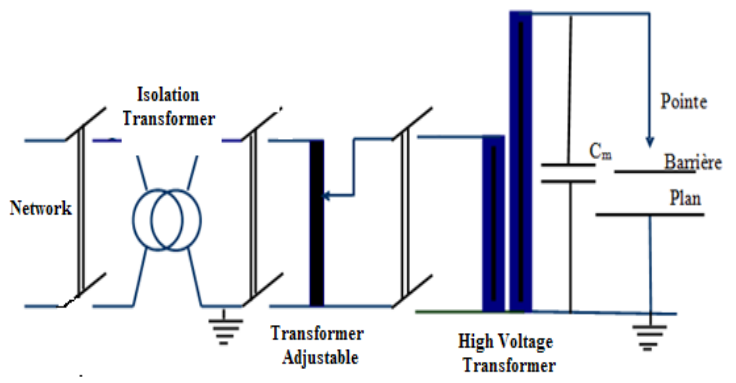

Fig. 1. Circuit probationary industrial realizes a frequency

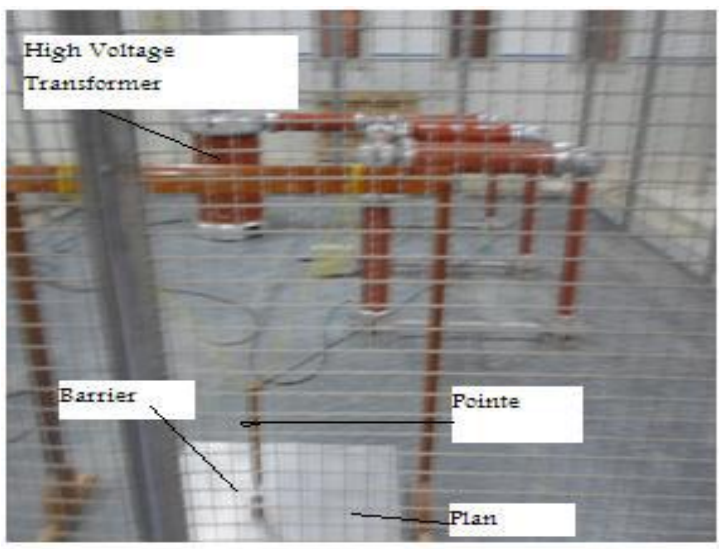

Fig. 2. View of real test cell

The barrier is mounted vertically between the electrodes Fig 2. Its surfaces are checked after each breakdown. The position of the barrier is defined by the ratio $(\mathrm{a} / \mathrm{d})$, where (a) is the point-barrier distance and dis the point-plan electrode gap.

\section{DESIGN OF A FUZZY SYSTEM FOR PREDICTION}

In this paper a hierarchical structure of Sugeno model was adopted to predict the breakdown voltage in terms of the relative position $R$ and the Width of the barrier, for two values of relative permittivity and the hole Fig. 3 (Fuzzy logic system).

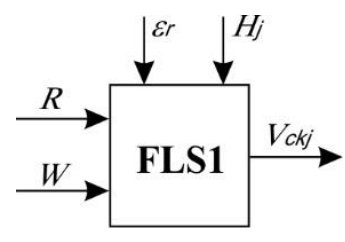

Fig. 3. Fuzzy logic system

Each input variable ( $\mathrm{R}$ or $\mathrm{W}$ ) is quantified into their fuzzy subsets: small $\mathrm{S}$, medium $\mathrm{M}$ and large L.

Memberships of these subsets have triangular shapes (Fig. 4 and 5).

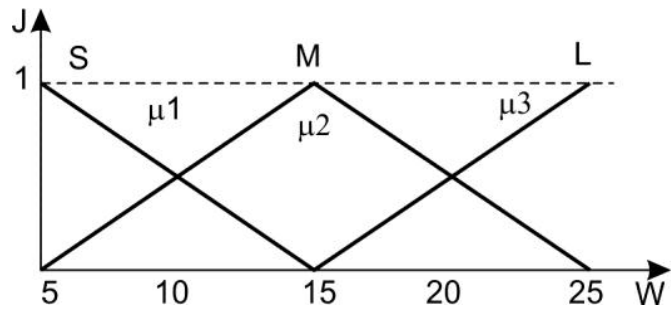

Fig. 4. Function of membership of the width $\mathrm{W}(\mathrm{cm})$ of the barrier

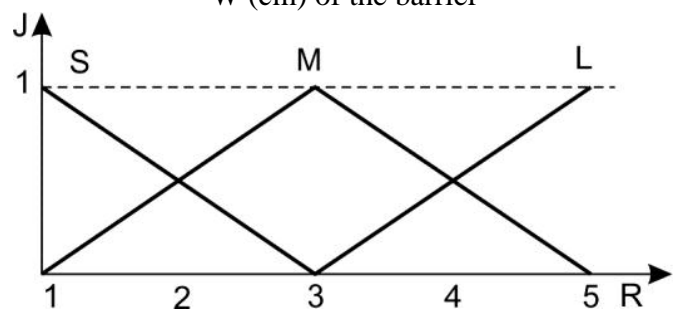

Fig. 5. Function membership of the distance R (cm)

Tab.1. Rule base of the fuzzy systems FLS Fj $_{\text {kj }}$
\begin{tabular}{|l|c|c|c|}
\hline $\mathrm{W}(\mathrm{mm})$ & $\mathrm{S}$ & $\mathrm{M}$ & $\mathrm{L}$ \\
\cline { 1 - 1 } $\mathrm{R}(\mathrm{cm})$ & & $V_{12}$ & $V_{13}$ \\
\hline $\mathrm{S}$ & $V_{11}$ & $V_{22}$ & $V_{23}$ \\
\hline $\mathrm{M}$ & $V_{21}$ & $V_{32}$ & $V_{33}$ \\
\hline $\mathrm{L}$ & $V_{31}$ &
\end{tabular}

Where: Vij are values of the output of the fuzzy rules, for $\varepsilon_{r}=\varepsilon_{k}$ and $H=H_{j}$

The expression of the output of the value fuzzy system is

$$
V_{C}(k j)=\frac{\sum \quad \mu_{j}(R) \gamma_{l}(W) V j l(k j)}{\sum \quad \mu_{j}(R) \gamma_{l}(W)}
$$

Membership function as a function of distance:

$$
\begin{aligned}
& \mu_{1}(R)=\max \left(\frac{3-R}{2}, 0\right) \rightarrow e^{-\left(\frac{R-1}{\sigma}\right)^{2}} \\
& \mu_{2}(R)=\max \left[\min \left(\frac{R-1}{2},\left(\frac{5-R}{2}\right)\right), 0\right] \rightarrow e^{-\left(\frac{R-3}{\sigma}\right)^{2}} \\
& \mu_{3}(R)=\max \left(\frac{R-3}{2}, 0\right) \rightarrow e^{-\left(\frac{R-5}{\sigma}\right)^{2}}
\end{aligned}
$$


$\gamma_{1}(W)=\max \left(\frac{15-W}{10}, 0\right) \rightarrow e^{-\left(\frac{W-5}{\sigma}\right)^{2}}$

$\gamma_{2}(W)=\max \left[0, \min \left(\frac{w-5}{10},\left(\frac{25-w}{10}\right)\right)\right] \rightarrow$

$e^{-\left(\frac{w-15}{\sigma}\right)^{2}}$

$\gamma_{3}(W)=\max \left(0, \frac{w-15}{10}\right) \rightarrow e^{-\left(\frac{w-25}{\sigma}\right)^{2}}$

The relative permittivity $\varepsilon_{r}$ has been quantified into two fuzzy values (3.3 and 6).

The hole $\mathrm{H}$ has been quantified into two values (4mm and $12 \mathrm{~mm}$ ).

Their membership function are presented in Fig 6 and 7).

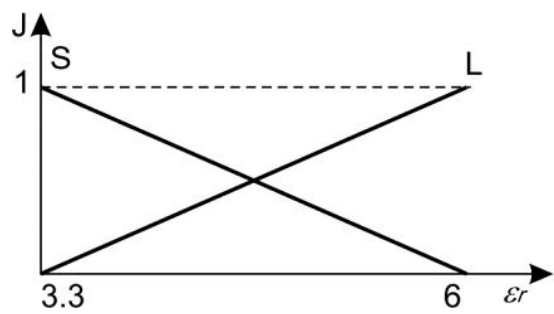

Fig. 6. Membership function of the nature of the barrier material

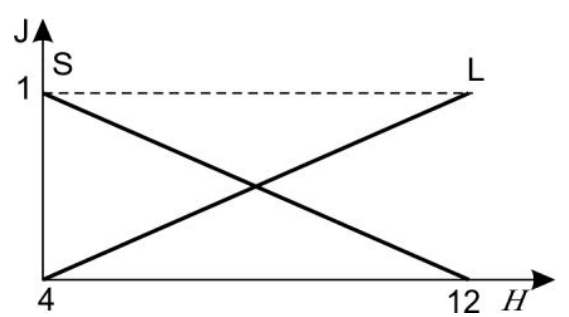

Fig. 7. Membership function of the hole $\mathrm{H}(\mathrm{mm})$

Rule of inferences of the fuzzy system FLC control:

FLC $_{\mathrm{i}} \quad 1 \leq i \leq h$

$\mathrm{IF}(\mathrm{R}$ and $\mathrm{S})$ and $(\mathrm{W}$ and $\mathrm{M})$ so $V_{C}=(\mathrm{R}=1, \mathrm{~W}=15) \Rightarrow S$ $\mathrm{IF}(\mathrm{R}$ and $\mathrm{S})$ and $(\mathrm{W}$ and $\mathrm{H})$ so $V_{C}=(\mathrm{R}=1, \mathrm{~W}=25) \Rightarrow S$ $\mathrm{IF}(\mathrm{R}$ and $\mathrm{S})$ and $(\mathrm{W}$ and $\mathrm{S})$ so $V_{C}=(\mathrm{R}=3, \mathrm{~W}=5) \Rightarrow M$ $\mathrm{IF}(\mathrm{R}$ and $\mathrm{S})$ and $(\mathrm{W}$ and $\mathrm{S})$ so $V_{C}=(\mathrm{R}=3, \mathrm{~W}=15) \Rightarrow M$ $\mathrm{IF}(\mathrm{R}$ and $\mathrm{S})$ and $(\mathrm{W}$ and $\mathrm{t} \mathrm{S})$ so $V_{C}=(\mathrm{R}=3, \mathrm{~W}=5) \Rightarrow M$ $\mathrm{IF}(\mathrm{R}$ and $\mathrm{S})$ and $(\mathrm{W}$ and $\mathrm{S})$ so $V_{C}=(\mathrm{R}=5, \mathrm{~W}=25) \Rightarrow H$ $\mathrm{IF}(\mathrm{R}$ and $\mathrm{S})$ and $(\mathrm{W}$ and $\mathrm{S})$ so $V_{C}=(\mathrm{R}=5, \mathrm{~W}=15) \Rightarrow H$ $\mathrm{IF}(\mathrm{R}$ and $\mathrm{S})$ and $(\mathrm{W}$ and $\mathrm{S})$ so $V_{C}=(\mathrm{R}=5, \mathrm{~W}=25) \Rightarrow H$ The whole fuzzy system can be presented by Fig 8 .

\begin{tabular}{|c|c|c|c|}
\cline { 2 - 4 } \multicolumn{1}{c|}{$\mathrm{W}$} & $\mathrm{S}$ & $\mathrm{T}$ & $\mathrm{M}$ \\
\cline { 3 - 4 } \multicolumn{1}{c|}{$\mathrm{R}$} & $\mathrm{S}$ & $\mathrm{H}$. 2. Inference of the Sugeno \\
\hline $\mathrm{S}$ & $V_{C m}(1,5)$ & $V_{C m}(1,15)$ & $V_{C m}(1,25)$ \\
\hline $\mathrm{H}$ & $V_{C m}(3,5$ & $V_{C m}(3,15)$ & $V_{C m}(3,25)$ \\
\hline $\mathrm{M}$ & $V_{C m}(3,5)$ & $V_{C m}(3,15)$ & $V_{C m}(3,25)$ \\
\hline
\end{tabular}

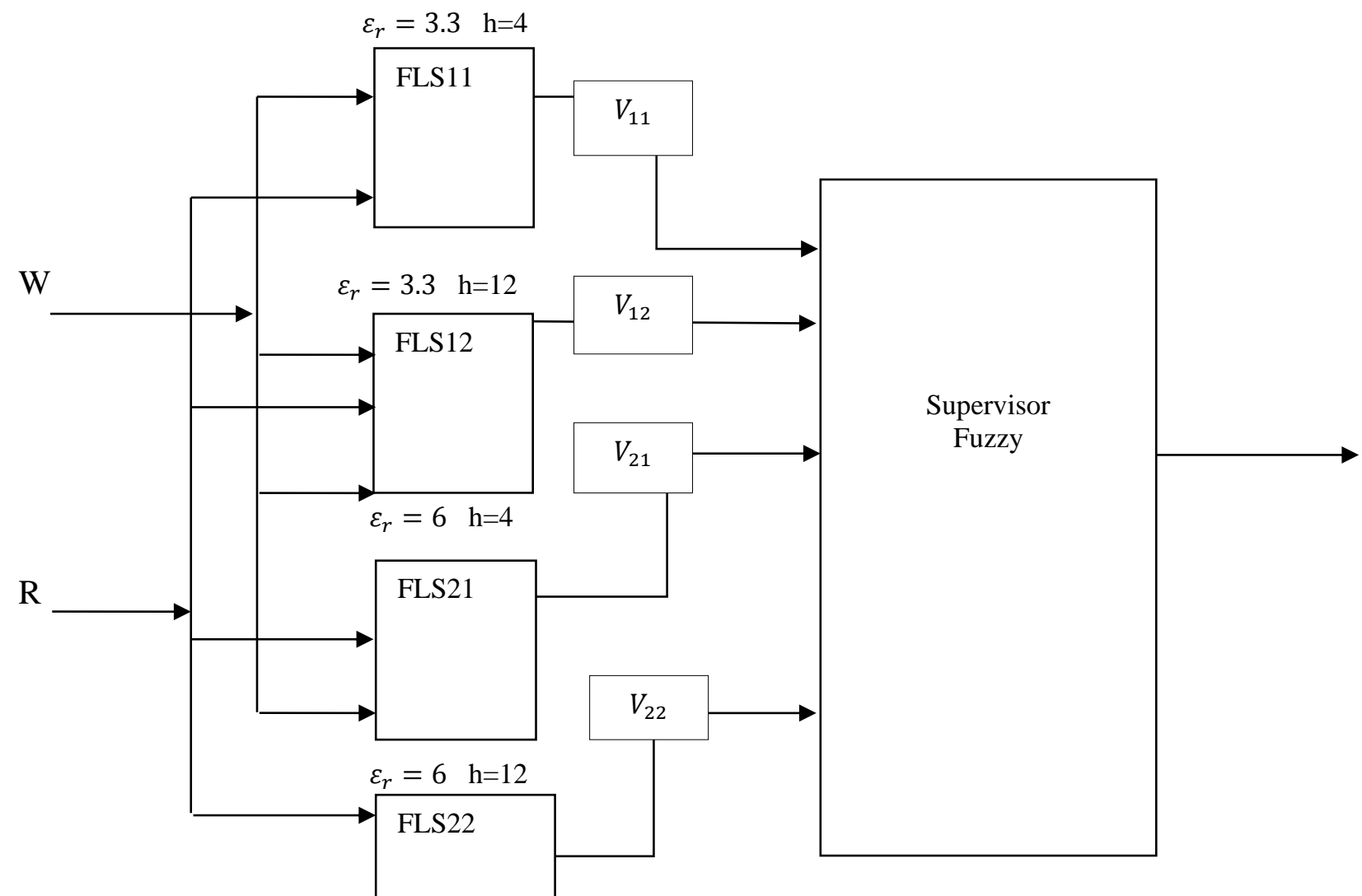

Fig. 8. Supervisor fuzzy 
Tab. 3. Fuzzy Controller

\begin{tabular}{|c|c|c|}
\hline $\mathrm{H}$ & $\varepsilon_{r}$ & $\mathrm{~S}$ \\
\hline $\mathrm{S}$ & $V_{C 1}$ & $V_{C 2}$ \\
\hline $\mathrm{H}$ & $V_{C 3}$ & $V_{C 4}$ \\
\hline
\end{tabular}

\section{RESULTS AND DISCUSSION}

\subsection{Prediction of the permittivity relative of the} barrier Bakelite $\varepsilon_{\mathbf{r}}=\mathbf{5 . 8 2}$ and the hole $\mathrm{H}=\mathbf{8 m m}$

Figures $(9,10,11$ and 12) present results of the training phase for different couple of values of $\mathrm{H}$ and $\boldsymbol{\varepsilon}_{\mathbf{r}}:\left(\mathrm{H}, \boldsymbol{\varepsilon}_{\mathbf{r}}\right)=(12,6),(4,6),(12,3.3),(4,3.3)$.

The validation phase consists in the prediction of the DC breakdown voltage for $\varepsilon_{\mathrm{r}}=5.82$ and $\mathrm{H}$ $=04 \mathrm{~mm}, 8$ and $12 \mathrm{~mm}$ and for $\varepsilon_{\mathrm{r}}=3.3$ and 6 for $\mathrm{H}=8 \mathrm{~mm}$ obtained results are compared to experimental ones in, figures (13 - 17).

Observing these figures, it is clear that the obtained prediction values of the DC breakdown voltage are close to experimental ones.

\subsection{Influence of the permittivity relative of the barrier on the breakdown voltage}

Figures $(10,12$, and 16) shows the experimental and predicted breakdown voltage as a function of the relative position of the barrier values of the barrier for different width $(5 \mathrm{~cm}, 10 \mathrm{~cm}, 15 \mathrm{~cm}, 20$ $\mathrm{cm}$ and $25 \mathrm{~cm}$ ) of the barrier. The hole in the barrier is $(4 \mathrm{~mm})$. Different permittivity is $(3.3,5.82$ and $6)$. Different distances between the point and the barrier $(1 \mathrm{~cm}$ to $5 \mathrm{~cm})$ were studied.

The insertion of the barrier has a significant influence on the breakdown voltage. This means that the founded model by the fuzzy logic method is perfect.

\subsection{Influence of the hole in the barrier on the breakdown voltage}

In this test, Figures $(9,10$, and 13) holes in the middle of the barrier varies $(4 \mathrm{~mm}, 8 \mathrm{~mm}$ and $12 \mathrm{~mm}$ ) the relative position of the barrier values for $(1 \mathrm{~cm}$ to $5 \mathrm{~cm})$, different width $(5 \mathrm{~cm} 10 \mathrm{~cm}, 15 \mathrm{~cm}, 20 \mathrm{~cm}$, and $25 \mathrm{~cm})$, the permittivity of the barrier is $\left(\varepsilon_{\mathrm{r}}=6\right.$ ).

Figures $(14,15$, and 16) holes in the middle of the barrier varies $(4 \mathrm{~mm}, 8 \mathrm{~mm}$ and $12 \mathrm{~mm})$ the relative position of the barrier values for $(1 \mathrm{~cm}$ to 5 $\mathrm{cm})$ different width $(5 \mathrm{~cm}, 10 \mathrm{~cm}, 15 \mathrm{~cm}, 20 \mathrm{~cm}$, and $25 \mathrm{~cm})$, the permittivity of the barrier is $\left(\varepsilon_{\mathrm{r}}=5.82\right)$. In reviewing figures, we observe that the decrease of the breakdown voltage with the increase of the holes in middle of the barrier. This result could be interpreted by the fact that the electric charge that passes through the hole is low. When a diameter of hole is greater, a large part of the charging space passes through the hole as well. This can be interpreted by the fact that increasing the diameter of the hole.
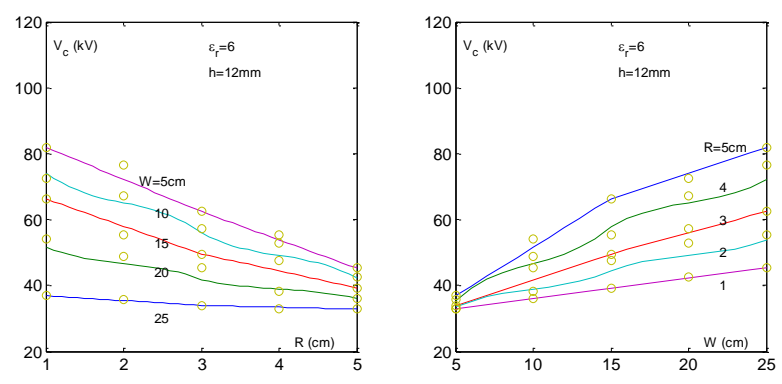

Fig. 9. Influence of the position and the width of the barrier on the DC voltage disruptive voltage for the hole $\mathrm{H}=12 \mathrm{~mm}$ and the relative permittivity $\varepsilon_{\mathrm{r}}=6$
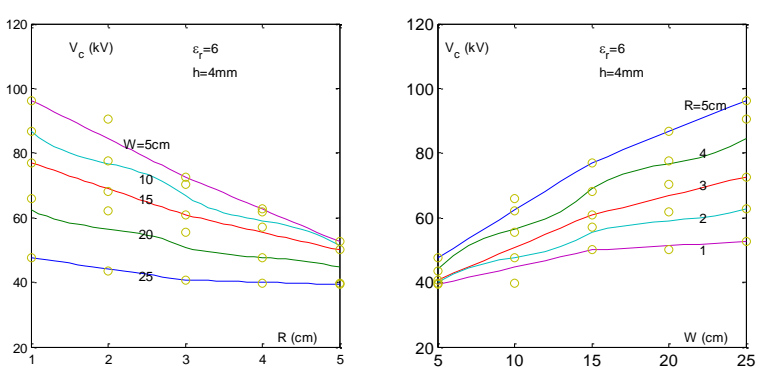

Fig. 10. Influence of the position and the width of the barrier on the DC voltage disruptive voltage for the hole $\mathrm{H}=4 \mathrm{~mm}$ and the relative permittivity $\varepsilon_{\mathrm{r}}=6$
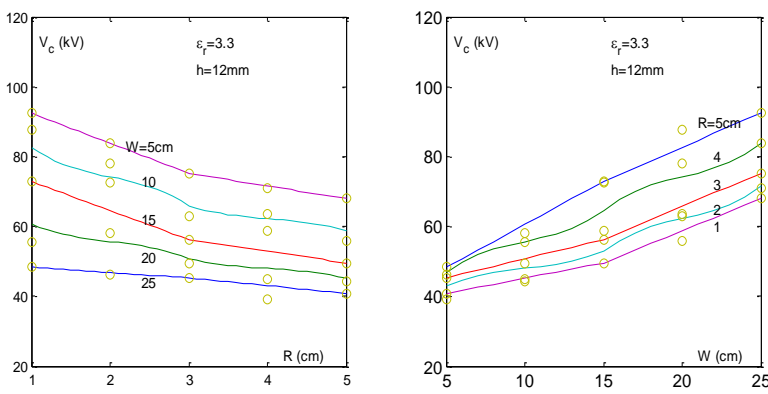

Fig. 11. Influence of the position and the width of the barrier on the DC voltage disruptive voltage for the hole $\mathrm{H}=12 \mathrm{~mm}$ and the relative permittivity $\varepsilon_{\mathrm{r}}=3.3$
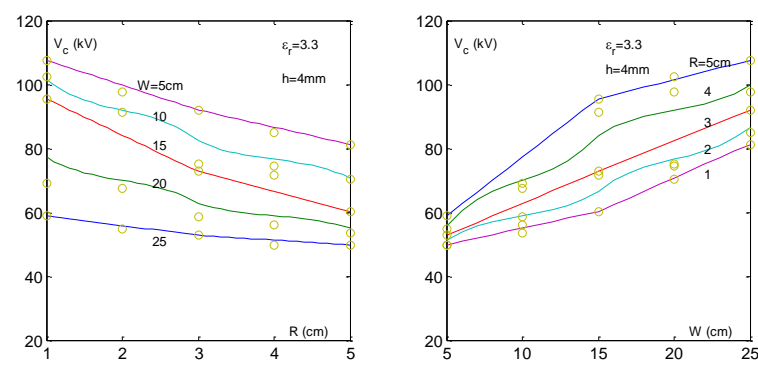

Fig. 12. Influence of the position and the width of the barrier on the DC voltage disruptive voltage for the hole $\mathrm{H}=4 \mathrm{~mm}$ and the relative permittivity $\varepsilon_{\mathrm{r}}=3.3$ 

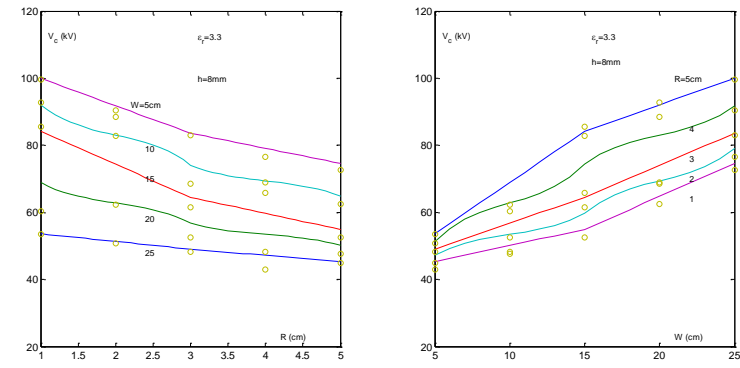

Fig. 13. Prediction of the breakdown voltage in terms of $\mathrm{R}$ and $\mathrm{W}$ for the hole $\mathrm{H}=8 \mathrm{~mm}$ and the relative permittivity $\varepsilon_{\mathrm{r}}=6$
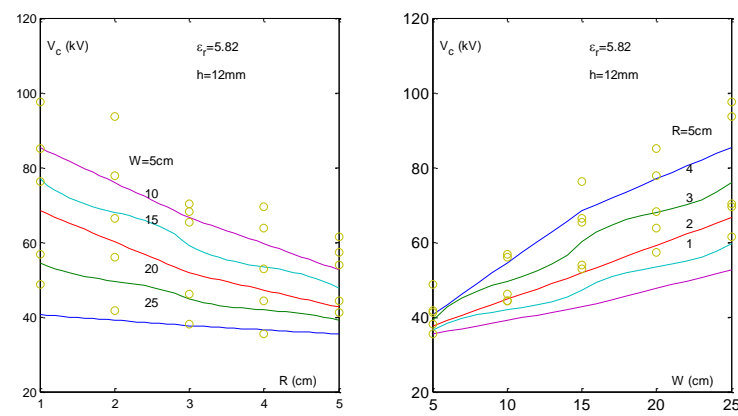

Fig. 14. Prediction of the breakdown voltage in terms of $\mathrm{R}$ and $\mathrm{W}$ for the hole $\mathrm{H}=12 \mathrm{~mm}$ and the relative permittivity $\varepsilon_{\mathrm{r}}=5.82$
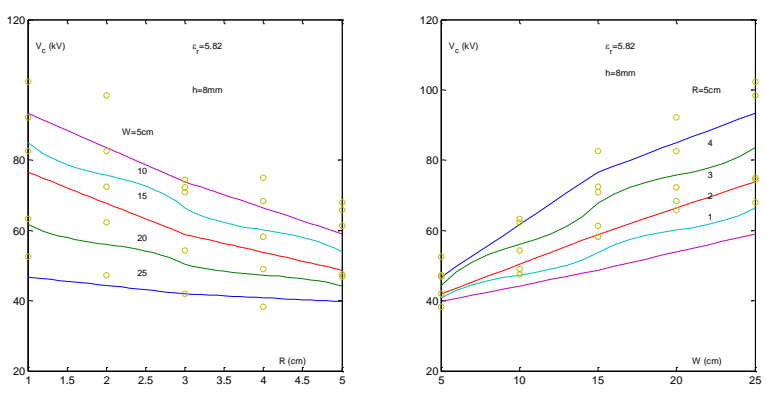

Fig. 15. Prediction of the breakdown voltage in terms of $\mathrm{R}$ and $\mathrm{W}$ for the hole $\mathrm{H}=8 \mathrm{~mm}$ and the relative permittivity $\varepsilon_{\mathrm{r}}=5.82$
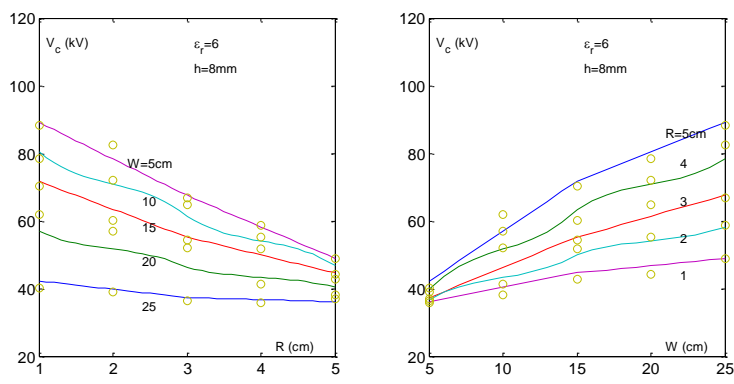

Fig. 16. Prediction of the breakdown voltage in terms of $\mathrm{R}$ and $\mathrm{W}$ for the hole $\mathrm{H}=4 \mathrm{~mm}$ and the relative permittivity $\varepsilon_{\mathrm{r}}=5.82$
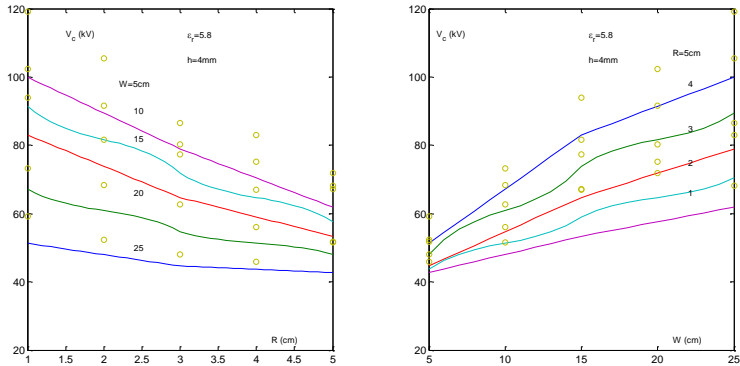

Fig. 17. Prediction of the breakdown voltage in terms of $\mathrm{R}$ and $\mathrm{W}$ for the hole $\mathrm{H}=8 \mathrm{~mm}$ and the relative permittivity $\varepsilon_{\mathrm{r}}=3.3$

\section{Conclusion}

In this paper, a new approach based on an expert system of fuzzy logic modelling has been proposed to predict the behaviour point-plan with different barrier used in high voltage. It is to value of the breakdown of the point to plane interval is close to experimental results. In this study the breakdown mechanism has been investigated with help of point-plan with barrier both experimentally and by simulation with MATLAB environment. In this study considering no change of physical condition like temperature and pressure. The effect of breakdown voltage on different insulation like (glass, bakelite and plexiglas), has also been studied. To observe the effect on insulation due to breakdown mechanism. The optimized maximum breakdown voltage is reduced as the holes on the barriers are made wider to a point where the barrier effect is not felt. The width of the hole depends on the length of the space. With a very small air gap a small hole on the stopping surface leads to a significant reduction in the breakdown voltage. It also depends on the location of the hole. If it is located at the central point of the barrier, it eliminates all the beneficial effect of the barrier.

For practical purposes, porous barriers are not recommended for voltage optimization. Sugeno models and adaptive fuzzy logic are some of the recent trends. These also provide better estimation and better tuning techniques. Has been very effective in predicting the breakdown voltage under DC conditions. As cannot claim about the optimality of the system, so it is better to model with all the available and algorithm choose the best estimate, gives very encouraging results. The simulation and experimental results confirmed that using a dielectric barrier in high voltage system configuration significantly increases the breakdown voltage.

\section{REFERENCES}

1. Iwata T, Okubo H, Kojima H. Positive streamer propagation and breakdown characteristics in nonuniform air gap. In High Voltage Engineering and Application (ICHVE), 2010. International 
Conference on. IEEE, 377-380.

https://doi.org/10.1109/ICHVE.2010.5640749.

2. Chvyreva A, Pemen AJM, Christen T. Investigation of streamer propagation along insulating surfaces. 31st International Conference on Phenomena in Ionized Gases (ICPIG), 2013; Granada, Spain.

3. Wang L, Meng X, Mei H, Guan Z. Characteristics of dstreamer propagation along insulation surface influence of dielectric material and shed configuration. 20th International Conference on Gas Discharges and their Applications, JUL 2014; Orleans, France.

4. Meng X, Mei H, Chen C, Wang L, Guan Z, Zhou J. Experimental research on influences of air pressure and humidity on characteristics of streamer propagation along insulation surfaces. Zhongguo Dianji Gongcheng Xuebao/ Proc. of the Chinese Society of Electrical Engineering, 2014; 34 (12): 1938-1947.

5. Mikropoulos PN, Zagkanas VN. A computational method for positive corona inception in the coaxial cylindrical electrode arrangement in air under variable atmospheric conditions. 16th International Symposium on High Voltage Engineering, Cape Town, South Africa, 2009.

6. Maglaras A, Kousiouris T, Topalis F, Katsaros D, Maglaras LA, Giannakopoulou K. Method of controlling corona effects and breakdown voltage of small air gaps stressed by impulse voltages. IEEE Electrical Insulation Conference (EIC), Ottawa, Canada, 2013.

7. Afa JT. Defective barrier on voltage optimization for small air gap. British Journal of Applied Science \& Technology, 2013; 3(4): 1301-1310. https://doi.org/10.9734/BJAST/2013/3653

8. Abderrazzaq MH. Analysis of electrical tree propagation through glass fiber barrier. IEEE Trans. Dielectr. Electr. Insul. 2012; 19(1): 305-311. https://doi.org/10.1109/TDEI.2012.6148532

9. Eduard P, Ivan P. Master time Dependent Modelling and Simulation of the Corona Discharge in Electrostatic Precipitators. University Linnaeus Sweden, 2014.

10. Karmakar S. An experimental study of air breakdown voltage and its effects on solid insulation. Journal of Electrical Systems, 2012;8 (2): 209-217

11. Maglaras A, Kousiouris T, Topalis F, Maglaras LA, Giannakopoulou K. Optimization of corona onset and breakdown voltage of small air gaps stressed by DC and impulse voltages. IEEE Euro Con, Zagreb, Croatia, 2013, 1207-1214.

https://doi.org/10.1109/EUROCON.2013.6625134

12. Hotta K, Iwata T, Kojima H. Impulse breakdown mechanism based on discharge propagation process under non-uniform electric field in air. In Electrical Insulation and Dielectric Phenomena (CEIDP), IEEE, 2011. Annual Report Conference: 534-537. https://doi.org/10.1109/CEIDP.2011.6232712

13. Shah BS, Parmar SB, Rathod JN, Pandya AS. Measurement of air breakdown voltage and electric Field using standard sphere gap method. International Journal for Research in Applied Science and Engineering Technology, 2014, 2 (VI): 180-186.

14. Phloymuk N, Pruksanubal AT, Thanuch, N Investigations on breakdown voltage of solid barrier under non- uniform electric field simulation and experiment. In Electrical Engineering/Electronics, Computer. Telecommunications and Information
Technology (ECTI- CON), 10th International Conference on Electrical Engineering/ Electronics, 2013:1-5 https://doi.org/10.1109/ECTICon.2013.6559489

15. Rouini A, Mahi D, Seghier T. Prediction the AC Breakdown Voltage in Point/Plan Air Gaps with Barrier Using Design of Experiments Journal TELKOMNIKA Indonesia Journal of Electrical Engineering 2014;12 (12): 8033-8041.

https://doi.org/10.11591/telkomnika.v12i12.6771

16. Topalis FV, Danikas MG. Breakdown in air gaps with solid Insulating barrier under impulse voltage stress, Facta Unversitas, SA, Electrical Engineering, 2005;18: 87-104.

17. Rouini A, Mahi D, Seghier T. Modelling of the AC breakdown voltage of point- plane air gaps with insulating barrier. International Journal of Electrical and Computer Engineering (IJECE), 2015; 05 (03): 391-402. https://doi.org/10.11591/ijece.v5i3

18. Subrata Karmakar. An experimental study of air breakdown voltage and its effects on solid insulation. journal of electrical systems,2012: 209-217.

19. Afa JT. Impulse breakdown of small air gap in electric field. Part I: Influence of barrier position. J. Appl. Sci. \& Technol; 2011;16(1 \& 2):58-62.

20. Hosokawa T, Kaneda T, Takahashi T, Yamamoto T, Morita T, Sekiya Y. DC breakdown characteristics in the gap with thin dielectric sheet in air. IEEE Transactions on Dielectrics and Electrical Insulation, 2011;18(3):822-832. https://doi.org/10.1109/TDEI.2011.5931071

21. Elham F, Hamid V. The Investigation of dielectric barrier impact on the breakdown voltage in high voltage systems by modelling and simulation. Power \& Energy Society General Meeting, 2015. https://doi.org/10.1109/PESGM.2015.7285653

22. Starikovskiy A, Nikipelov A, Rakitin A. Streamer breakdown development in undercritical electric field. Plasma Science, IEEE Transactions on, 2011; 39(11):2606-2607. https://doi.org/10.1109/TPS.2011.2160740

23. Mavroidis PN, Mikropoulos PN, Stassinopoulos CA. Impulse behavior of dielectric-covered rod-plane air gaps. IEEE Trans. on Dielectrics and Electrical Insulation, 2012;19 (2): 632-640. https://doi.org/10.1109/TDEI.2012.6180258

24. Mavroidis PN, Mikropoulos PN, Stassinopoulos CA. Lightning impulse behaviour of short rod-plane gaps with a dielectric-covered rod. IET Sci. Meas. Technol, 2010; 4 (2): 53-62. https://doi.org/10.1049/iet-smt.2008.0137

25. Lazaridis LA, Mikropoulos PN. Positive lightning impulse discharges along cylindrical insulating surfaces bridging a short rod-plane gap. IET Sci. Meas. Technol. 2010; 4(2): 63-75. https://doi.org/10.1049/iet-smt.2009.0082

26. Atten P, Adamiak K, Khaddour B, Coulomb JL. Simulation of corona dischargein configurations with a sharp electrode. Journal of Optoelectronics and Advanced Materials, 2004; 6: 1023-1028.

27. Lazaridis LA, Mikropoulos PN. Negative impulse flashover along cylindrical insulating surfaces bridging a short rod-plane gap under variable humidity. IEEE Trans. on Dielectrics and Electrical Insulation, 2010; 17 (5): 1585-1591. https://doi.org/10.1109/TDEI.2010.5595561

28. Mauseth F, Pedersen A. Streamer inception and propagation for air insulated rod-plane gaps with 
barriers. In Electrical Insulation and Dielectric Phenomena (CEIDP), IEEE 2012; Annual Report Conference on: 732-739. https://doi.org/10.1109/CEIDP.2012.6378884

29. Atten P, Adamiak K, Atrazhev V. Electric corona discharge simulation in the hyperbolic point - ground plane configuration. Annual Report Conference on Electrical Insulation and Dielectric Phenomena, 2002; Cancun, Mexico: 109-112.

30. Adamiak K, Atten P. Simulation de la décharge couronne en configuration pointe-plan. SFE3 ${ }^{\text {eme }}$ Congrès Annuel de la Société Française d'Electrostatique Toulouse, France:, 2002 ; 1-8.

31. Nourirad G, Izadi M, Gomes C, Ab Kadir MZA. Characterizing the breakdown behavior of Rodplane air gap under impulse over-voltage. IEEE 8th International Power Engineering and Optimization Conference (PEOCO), Langkawi, The Jewel of Kedah Malaysia, 2014. https://doi.org/10.1109/PEOCO.2014.6814471

32. Mohanty S, Ghosh S. Modeling of the breakdown voltage of Manila Paper in the presence of voids using adaptive fuzzy logic techniques. Proceedings of IEEE, $2009,3^{\text {rd }}$ International Conference on Power Systems, Kharagpur, India: 1-6. https://doi.org/10.1109/ICPWS.2009.5442738

33. Kolev NP, Chalashkanov NM. Modeling of partial discharge inception and extinction voltages using adaptive neuro-fuzzy inference system (ANFIS).2007, Proceedings IEEE $9^{\text {th }}$ International Conference on Solid Dielectrics, U.K: 605-608. https://doi.org/10.1109/ICSD.2007.4290886

34. Mohanty S, Ghosh S. Modeling of breakdown voltage of White Minilex Paper in the presence of voids under ac and dc conditions using fuzzy logic techniques. International Journal on Electric Power and Energy Systems Elsevier, 2010: 518-523.

35. Cross JA. Electrostatics Principles, Problems and Applications, Adam Hilger, Bristol 1987.

36. Hauschild W, Mosch W. Statistical techniques for high-voltage engineering. IET 1992.

Received 2018-01-07

Accepted 2018-06-14

Available online 2018-07-03

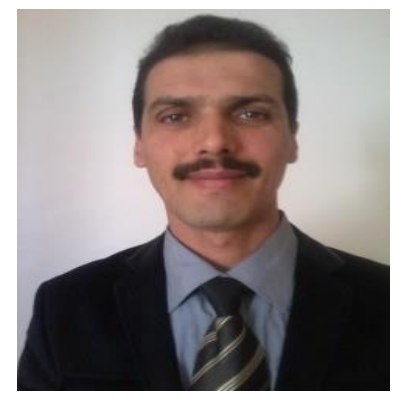

Dr Abdelghani ROUINI was born in Djelfa Algeria, on March 1973. He received the doctorate degree in electrical engineering from the University of Laghouat, Algeria.

Since May 2012 is an assistant Professor at the same department.

$\mathrm{He}$ is research in LAADI Laboratory Djelfa , University Algeria. His main research area includes Modeling of electrical Drives Control, Artificial Intelligence and renewable Energy Systems Controls.

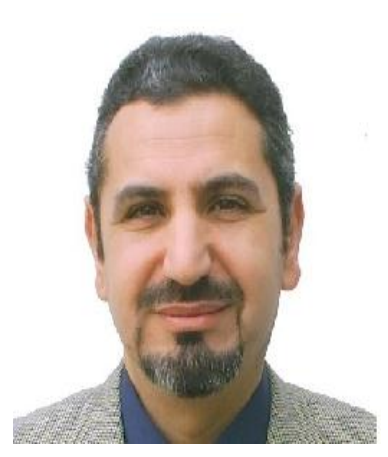

Prof Nabil DERBEL was born in Sfax (Tunisia) in April 1962. He received his engineering Diploma from the Ecole Nationale d'Ingénieurs of Sfax in1986, the Diplôme of études Approfondies in Automatic control from the Institut National of Sciences Appliquées of Toulouse in 1986, the Doctorat d'Université degree from the Laboratoire d'Automatique et d'Analyse des Systèmes de Toulouse in 1989, and the Doctorat d'Etat degree from the Ecole Nationale d'Ingénieurs of Tunis. He joined the Tunisian University in 1989, where he held different position involved in research and education. Currently, he is a full Professor (First Class) of Automatic Control at the Ecole Nationale d'Ingénieurs de Sfax. He is an IEEE Senior member. His current interests include: Optimal Control, Complex Systems, Fuzzy Logic, Neural Networks, Genetic Algorithm. He is the author and the co-author of more than 80 papers published in international Journals and of more than 500 papers published in international conference $\mathrm{He}$ was the Head of the Research Unit «Intelligent Control, design and optimisation of complex systems» from 2001 to 2006.

He has been the Director of Study and the Vice Director of the National Engineering School of Sfax from 2011 to 2014.

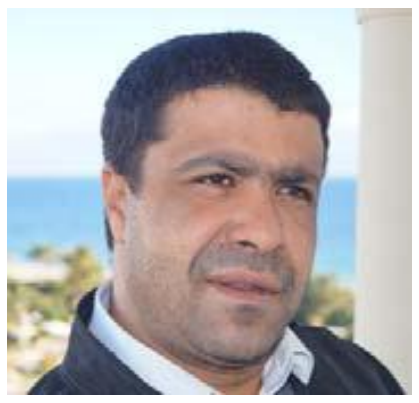

\section{Prof Ahmed}

\section{HAFAIFA}

is the founder of the Applied automation and Industrial Diagnostic Laboratory at the University of Djelfa. $\mathrm{He}$ is the supervisor of many PhD Students and he is the coordinator of several industrial.

Research projects within the applied automatic diagnostics and reliability of industrial systems. His research area of interests includes the modelling and control in industrial systems, the diagnosis and new reliability engineering, fault detection and isolation in industrials process, intelligent system based on fuzzy logic and neural networks. He is acting as an expert in several national and internationals commissions and collaboration research activities. He has participated in several international research projects and has led several national research projects.

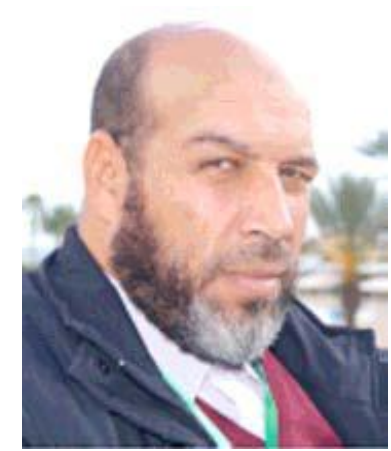

Prof Abdellah KOUZOU (IEEE\& IACSIT Senior member, IFAC, IAENG \& IISRO member) was born in Djelfa, Algeria.

$\mathrm{He}$ received the State Engineer degree, the Magister, the $\mathrm{PhD}$, and the Habilitation from University of Tiaret, Algeria, Superior National School 
respectively. He has been a researcher with Technische Universität of Muenchen in Germany. Currently he is an associate professor with Djelfa University in Algeria and the president of the Scientific Council of the Sciences and Technology Faculty at the same university where he is the supervisor of many PhD Students. He participated in several research projects and has led several research projects. He is the founder of the Power Electronics and Power Quality research group at the University of Djelfa, Algeria.

Furthermore, he has been an invited researcher and collaborator researcher many times at Texas A\&M University at Qatar. He is a member of many editorial boards for several scientific journals.

$\mathrm{He}$ is the coordinator of the Algerian IEEE Power Electronics Chapter and the chair of the sub-committee on FACTs and HVDC under the PETC/IEEE-IES. The main research interests Dr include Active Power Filtering techniques, Power Quality issues, Power Electronics Devices, Application of Power electronics in Renewable Energies and Application of meta-heuristics optimization algorithms. He has published more than 100 papers in Journals and conferences within his research domains. 